\title{
Analysis of IT Project Assessment Methods in Enterprise Project Management
}

\author{
Zhujing $^{1, a}$, Penglu ${ }^{2, b}$, and Zhang chunxia ${ }^{3, c}$ \\ ${ }^{1} \mathrm{NC}-\mathrm{MERB}$ of RIOH, No. 8, West Tucheng Road, Haidian District, Beijing, China \\ ${ }^{2} \mathrm{NC}-\mathrm{MERB}$ of RIOH, No. 8, West Tucheng Road, Haidian District, Beijing, China \\ ${ }^{3} \mathrm{NC}$-MERB of RIOH, No. 8, West Tucheng Road, Haidian District, Beijing, China

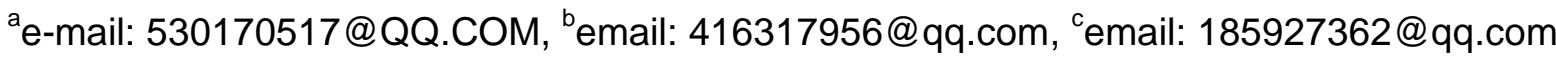

Keywords: enterprise, project management, IT project, assessment method.

\begin{abstract}
. with economic and social development, market competition grows fiercer and some enterprises suffer profit decrease. In order to improve enterprise project management, managers should make use of information technology and meanwhile improve assessment of IT projects. Such assessment cannot only be taken as indicators for quality of an enterprise's previous IT projects, but also provide reference for future IT projects. In this paper, IT project assessment methods in the enterprise project management system is studied.
\end{abstract}

\section{Preface}

IT project assessment refers to assessment of the whole process of an IT project from project proposal, management, control and appraisal. Currently, as market competition intensifies, all industries are using information technologies to realize control. IT projects involve SCM, DRP, ERP and other information systems, which have all seen application in real-world practice. Moreover, as the IT projects of enterprises increase, how to control and coordinate these projects becomes a focus of enterprise project management. Analysis and prediction before the projects, control during the projects and assessment after the project are the major components of IT project assessment.

\section{Significance and effect of IT project assessment}

\subsection{To provide measuring tools for enterprises}

IT project assessment can provide some measuring tools, such as quality check tables, for enterprise management. With these tools, the enterprise can realize better control of the progress and quality of projects. By IT project assessment, the managers can make rational estimate of resources required in future projects and improve the efficiency of IT project management. Furthermore, IT project assessment can estimate the future profit of a project and facilitate the enterprises' adjustment of strategies.

\subsection{To promote rational distribution of enterprise resources}

Some enterprises only have limited resources, and to select appropriate methods to promote the enterprise's development is a major part of project assessment. By using the IT project assessment method, enterprises can compare different projects, analyzing their advantages and disadvantages, learn about the actual conditions of the projects, and direct resources to quality projects [1].

\section{Specific Methods of IT Project Assessment}

\subsection{Balanced Scorecard}

In the 1980s, the balanced scorecard was invented in America to analyze enterprise performance from different perspectives. It not only involves general financial evaluation, but covers customer 
satisfaction, internal business procedures and learning innovation. All perspectives can be divided into the following aspects: target (to provide services or products to consumers), task (to become suppliers required by customers, for instance), and measuring indicators (product's cycles). The balanced scorecard can be used to assess IT projects and four measuring aspects can be established: customer orientation, future orientation, internal procedures and business profit, based on which the measuring methods can be set up. The detailed measuring indicators include the proportion of outsourced IT projects, credibility of the IT department, customer satisfaction, etc. [2]

\section{2 multi-objective multi-criterion method}

In practice, the value of a project should not be judged only by money, but also by other measures. This multi-objective and multi-criterion method requires the enterprise managers to assess the value of the enterprise's projects from different angles. For example, enterprises can establish a system of indicators, corresponding weights and evaluation objectives, and assess the final results by efficiency rather than money.

In this method, staff at different levels in the enterprise need to provide opinions about the value of different elements of projects. In this way, before approval of a project, different opinions are encouraged to reflect the conflicts [3]. This multi-objective and multi-criterion method is suitable for selection of different solutions and control of projects.

\subsection{Present value-based assessment method}

The present value-based assessment method is assessment of return on investment. That is to say, to analyze the expected value of cash flow yield, convert the discount rate into current value, and compare the value with invested cash flow. The enterprise can determine the threshold value to identify the minimum RoI. The advantage of RoI is that the decision-maker can use the same method to compare estimated return on investment of different projects. However, it also a drawback: the profit of many quality investments cannot be converted into cash flow, so the investment possibility of such potential projects is reduced.

\subsection{Return on management method}

The generated new system can bring in profit to the enterprise, which is called the return on management (management benefits). This return on management is defined as benefits that are the sum of the total profits plus different resources minus the management expenditure and the costs. Return of the new system is the difference of returns before and after introduction of the new system.

Before an enterprise launches an IT project, the IT system, the estimated profit, the estimated resource cost and contribution change, so the return on management changes accordingly. The method of return on management is a method that assesses the information system according to the past trend.

\subsection{Value analysis method}

This method tends to assess more general concepts of efficiency, the most common of which is implicit efficiency. It focuses more on value development than on saving costs. When the value analysis method, the Delphi scoring model is used. By assessing and scoring the implicit value, the enterprise can combine the financial data, project management qualitative method and the manager's subjective experience [4].

Enterprises can make more profits by using IT systems. The value analysis method can use different statistical methods like clustering analysis method, to categorize similar benefits into one category and then know the value of efficiency. The value analysis method assign weights to the benefits for calculation. Project assessment and marketing have similar assessments of new products. Research on this field means how to exchange attributes of different products in consumption decision-making. Another method is combined assessment. Combined assessment converts analysis of each target user into an efficiency factor of the target to learn about the consumer's preference. 


\subsection{Cost-benefit analysis}

Cost-benefit analysis, shortened as CBA, needs to find possible costs and benefits of projects, and describes currency value of different aspects. For instance, many elements in cost and benefits do not have market value, but the cost and benefits of these elements are not investment subjects. The cost-benefit analysis method can solve this problem. On the basis of the valuation theory, all costs and benefits can be described as currency values [5]. The cost and benefits calculated can be used in decision-making models based on the standard RoI method.

\section{Application of IT project assessment in enterprise project management}

A is a large enterprise specializing in new energy management. The EPR project of A is analyzed. In order to control the ERP project, the management quality of the EPR project needs to be analyzed, and a scientific indicator system should be established according to the multi-objective and multi-criterion method. The following indicators are obtained by the enterprise's project team.

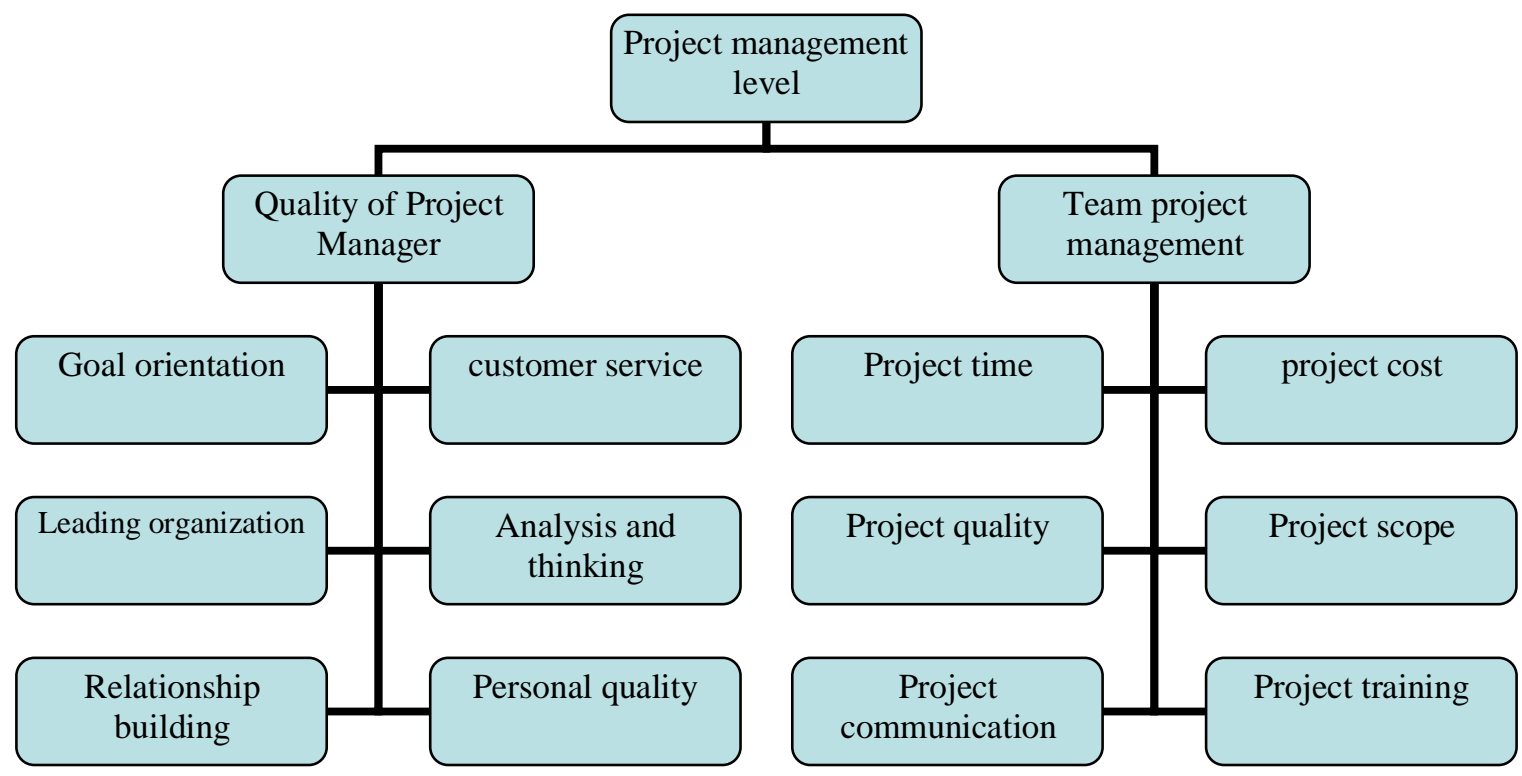

Figure 1. Multi-objective multi-criterion indicator system

Figure 1 shows the criterion layer of the multi-objective and multi-criterion system. The project time management standards include the following indicators: 1. to divide the project tasks and describe responsibilities; 2 . to design the task plan schedule; 3 . to sequence the tasks in the project; 4 . to compare progress of the project. The project is then scored according to the indicator system to obtain the indicator's function value. The weighted assessment method is used to obtain the overall assessment score of the whole project [6].

The control threshold for project management level is set up according to the actual conditions. If the assessment result does not match the threshold, project control measurs should be adopted. As the ERP project takes long time and complex procedures, control of the project cannot be realized by mere project assessment. Important control points should be set up in operation and the assessment process should be started when the project approaches the control points.

\section{Conclusion}

In conclusion, IT project assessment is an important part in enterprise project management. Managers should not only establish scientific assessment systems, but also have the big picture in mind and make correct judgement of all aspects to improve the enterprise's core competitive force.

\section{Acknowledgment}

Fund: Central Public Welfare Scientific Research Institute of basic research special funds (RIOH). 


\section{References}

[1] Guan Chunhua, Wang Dongsheng. Study on evaluation index system of construction project management capacity of construction enterprises [J]. Value engineering, 2018,37 (01): 71-72.

[2] Fang Xin. Research on application design of extension in project-based enterprise project management capability evaluation [J]. Special Economic Zone, 2018 (09): 139-142.

[3] LIN Gui. Reflections on the evaluation of project management ability of real estate enterprises in the context of multiple projects [J]. Housing and real estate, 2018 (18): 3.

[4] Ding Mingying. Discussion on the implementation and evaluation of enterprise information system project management [J]. Computer knowledge and technology, 2018,14 (06): 190-191.

[5] Chen Fei. Trying to establish a scientific evaluation system for project management of construction enterprises [J]. China management informatization, 2017,20 (24): 66-67.

[6] Wang Min, Yang Jingyu. Research on maturity evaluation model of construction enterprise organizational project management [J]. Value engineering, 2016,35 (13): 80-82. 